\title{
COMPARISON OF PROBLEM BASED LEARNING WITH TRADITIONAL LECTURES AMONG FIRST YEAR MEDICAL STUDENTS IN PHYSIOLOGY
}

\author{
Evelyn Thomas ${ }^{1}$
}

${ }^{1}$ Assistant Professor, Department of Physiology, Govt. Medical College, Kottayam.

ABSTRACT: BACKGROUND: Problem based learning has emerged as an effective teaching learning method. Students taught by the problem based learning method have better problem solving skills and better long-term memory than those taught by traditional lectures.

OBJECTIVE: To compare the effectiveness of problem based learning with that of traditional lecture method.

METHODOLOGY: First MBBS students $(n=127)$ were divided into two groups. One group was taught a topic from Applied Physiology by Problem based learning method and other group was taught the same topic by lecture method. Later the methods were reversed between the two groups with another topic of the same weightage. Finally feedback was obtained and post test conducted. The marks obtained in post test were analysed using SPSS software.

RESULTS: The average post test score after Problem based learning (12.728) was significantly higher than that after lecture (11.079). Also majority of students liked to include Problem based learning method in curriculum for teaching Physiology.

CONCLUSION: Problem based learning is a more effective method in teaching applied Physiology when compared to traditional lectures.

KEYWORDS: Problem Based Learning, Physiology, Teaching-Learning Methods.

HOW TO CITE THIS ARTICLE: Evelyn Thomas. "Comparison of Problem Based Learning with Traditional Lectures among First Year Medical Students in Physiology." Journal of Evolution of Medical and Dental Sciences 2015; Vol. 4, Issue 93, November 19; Page: 15827-15830, DOI: 10.14260/jemds/2015/2293.

INTRODUCTION: BACKGROUND: In most medical colleges in India, students are being taught by means of didactic lectures, tutorials and practical classes. These methods are mainly teacher centred and have less participation from the students. Though these graduates acquire reasonably good knowledge of medical science, they lack certain skills, like problem solving skills, communication skills, etc., which are the most important clinical competencies required of a medical graduate. Studies have even shown that the learning experience of basic medical sciences can be improved by better clinical integration of these subjects. ${ }^{1}$

In the traditional curriculum followed by most medical colleges in India, the basic medical subjects like Anatomy, Physiology and Biochemistry are taught in isolation without any integration with the clinical subjects. An integrated curriculum would provide a better meaningful learning experience and help students apply the knowledge gathered in basic medical sciences to the care of the patients. ${ }^{2}$ As a first move towards the concept of integrated teaching, a closely related Problem based learning approach was introduced in many medical schools outside India.

Problem based learning (PBL) is a student centred novel educational approach which has been implemented recently in different medical schools worldwide.

Financial or Other, Competing Interest: None.

Submission 29-10-2015, Peer Review 30-10-2015,

Acceptance 09-11-2015, Published 17-11-2015.

Corresponding Author:

Dr. Evelyn Thomas,

Assistant Professor,

Department of Physiology,

Govt. Medical College, Kottayam, Kerala.

E-mail: evelynphysiology@gmail.com

DOI:10.14260/jemds/2015/2933.
The problem based approach, not only enhances the knowledge but also helps the development of problem solving, critical thinking, communication, collaboration and self-directed learning skills. It also helps deliver medical education in an integrated and focussed manner. It comprises of active learning where students emphasize more on understanding than memorising when compared to traditional passive lectures. Problem based learning (PBL) is a process of learning using a problem as a starting point.

In a typical Problem based learning approach, students are presented with a clinical case scenario. PBL learning process involves the following steps: students in small groups (5-8) attempt to define a problem, generate a hypothesis, set up learning objectives, decide the learning activities required, assign learning activities to each, do self-directed study using available resources, share their learning in the group and finally summarise and integrate their learning. ${ }^{3}$ Thus they use the clinical problem as a focus to acquire knowledge which meets the learning objectives.

Regarding basic medical sciences like Physiology, knowledge learned in context of a clinical case is better comprehended and more easily applied by medical students than knowledge learned in isolation. Medical educators have even found that implementation of Problem based learning in Physiology has even promoted a more deep approach learning in students rather than surface approach. ${ }^{4}$

The deep approach is the most desirable way of learning which is closely linked to intellectual processes. Many studies over the years have proved that students who had used the Problem based learning method even showed better interpersonal skills and better attitude towards patients. ${ }^{5}$ Also it promotes students to be life-long learners in medical education. 
PBL requires tutors to function as facilitators who support and guide the students rather than acting as providers of information. The ability of tutors to explain concepts in a easily understandable way and ability to communicate informally with students has a greater impact on learning at each of the PBL phases. ${ }^{6}$ Thus the implementation of Problem based learning requires careful planning, faculty training, commitment and even proper understanding of the philosophy behind its implementation.

The effectiveness of Problem based learning also depends on the tutor's quality and the student's motivation. Medical educators have even reported that rigorous and practical training should be given to tutors and students to understand the philosophy of Problem based learning.? Studies have shown that faculty training workshops shall help understand the meaning of PBL, steps of PBL, importance of group dynamics and student responsibilities in PBL. ${ }^{8}$ The present study is aimed to compare the effectiveness of problem based learning with that of traditional lectures in first year medical students in the subject of Physiology.

METHODOLOGY: The present study was an experimental study conducted in 127 first MBBS students at the Department of Physiology of Govt Medical College Kottayam. The study was conducted for a period of 3 months. All the students voluntarily agreed for participating in the study. Institutional Ethical Clearance was obtained and written informed consent taken from the students.

Initially, the faculty selected were given an orientation and briefing regarding the principles, methodology and the practice of a Problem based learning session. The students were also oriented regarding Problem based learning, its pre-requisites, the methodology of Problem based learning and the role of facilitator in this methodology. Two topics of equal weightage (High altitude Physiology and Deep Sea diving Physiology) were selected and clinical case scenarios were prepared from each topic.

Then the students were divided by lottery method into two batches A and B, containing 64 students and 63 students respectively. Both batches were further divided into smaller groups containing 8 or 9 students and each smaller group was allotted a facilitator/tutor from the faculty selected. The students were instructed to bring all the study materials or text books in Physiology available with them for all the sessions of Problem based learning.

The first session was for 1 hour, during which each smaller group of a batch was given a case scenario based on topic High altitude Physiology and each smaller group of B batch was given a case scenario based on Deep Sea diving Physiology. All the groups went through the case scenarios slowly, analysed it thoroughly, understood the meanings of difficult and novel terms, identified their learning needs and set up their objectives.

Then they were given sufficient time for self-study and discussion in the group. The second session held 1 week later, which was for 2 hours. In the first one hour, the students shared their knowledge regarding the topic, cleared their doubts and discussed their problem in depth. In the second hour, there was a presentation of the topic in which each student presented a part of the concerned topic. In the both sessions the faculty guided them, helped them set up their objectives and clarified their doubts. The Problem based learning session was finally concluded by obtaining a questionnaire from the students regarding the conduct of PBL, with questions pertaining to advantages, disadvantages and their opinion of PBL.

This was followed by a lecture class for 1 hour each on High altitude physiology for B batch and Deep Sea diving physiology for A batch. Thus each student was exposed to both the methods, one method for each topic. A post test was conducted on each topic for both batches. The post test scores were analysed by SPSS software.

RESULTS: The mean post test scores of traditional lectures and Problem based learning are 11.079 and 12.728 respectively, which are given in Table 1 below. This mean post test score obtained after Problem based learning was found to be significantly higher ( $p$ value 0.001 ) compared to the mean post test score obtained after traditional lecture.

\begin{tabular}{|c|c|c|c|}
\hline Post Test Scores n= 127 & Mean & SD & $\begin{array}{c}\text { P } \\
\text { Value }\end{array}$ \\
\hline Traditional Lecture & 11.079 & 2.9623 & \multirow{2}{*}{0.001} \\
\hline Problem based learning & 12.728 & 2.4002 & \\
\cline { 1 - 2 } Table 1: Comparison of Post Test Scores of Traditional \\
Lecture and Problem Based Learning \\
\hline
\end{tabular}

Questionnaire analysis revealed that majority (89\%) of students strongly recommended to include PBL in medical curriculum for some applied Physiology topics which is shown in Table 2 below and approximately 11\% of students did not want to include it in their curriculum.

\begin{tabular}{|c|c|}
\hline $\begin{array}{c}\text { Students view on whether to } \\
\text { include PBL in curriculum }\end{array}$ & $\mathbf{\%}$ \\
\hline Yes & 89 \\
\hline No & 11 \\
\hline $\begin{array}{c}\text { Table 2: Students view on whether to } \\
\text { include PBL in curriculum }\end{array}$ \\
\hline
\end{tabular}

Among the merits of Problem based learning outlined by students in the questionnaire are, more interactive (29\%), enhances better memory (6\%), enhances better problem solving skills (12\%), self directed learning (9\%), less boring $(12 \%)$ and miscellaneous or others (31\%) which are shown in Table 3 below. The miscellaneous includes better understanding, group discussion, enthusiastic and more satisfactory.

\begin{tabular}{|c|c|}
\hline Merits of PBL & \% \\
\hline Less boring & $11.80 \%$ \\
\hline More interactive & $29.10 \%$ \\
\hline Self-directed learning & $8.70 \%$ \\
\hline Better problem solving skills & $12.60 \%$ \\
\hline Better memory & $6.30 \%$ \\
\hline Others & $31.50 \%$ \\
\hline Table 3: Merits of PBL outlined by students \\
\hline
\end{tabular}

DISCUSSION: Recently Problem based learning approaches are gaining popularity among medical students in different medical schools worldwide. Techniques like small group teaching, interactive resource sessions and self-study are 
used to introduce a Problem based learning module to the students. The Problem based learning involves the use of a clinical problem as a stimulus to learning. This helps the students to understand the linkage between the basic and applied clinical aspects of the topic being taught.

Using the existing infrastructure and faculty in the department, a Problem based learning module was designed and implemented. Firstly, the teachers and the students were oriented to the Problem based learning method as most of them had no previous experience with it. Thus a group of 127 first year undergraduates were exposed to both Problem based learning approach and traditional lectures for two equal weightage topics.

The present study compares the problem solving skills of students taught by Problem based learning approach and traditional lectures by comparing their mean post test scores. A significantly higher mean post test score was obtained in students with Problem based learning when compared to students with traditional lectures. This shows that basic sciences learning is more effective through Problem based learning approach.

But only certain applied Physiology topics are amenable to this PBL approach. So the success of Problem based learning depends on the problem chosen. A study by Bajaj Preeti et al., observed a significant improvement in the post test scores obtained after Problem based learning approach which reveals that PBL is an effective educational approach. ${ }^{9}$ Medical educators have even suggested that an intelligent combination of using both the PBL approach and a traditional method like large group lectures, tutorials and practical classes can provide the most effective training for undergraduate medical students. ${ }^{5}$

Also a subjective assessment of the student's opinion of PBL was done using a self-administered questionnaire after the PBL module. Majority of students expressed their interest to include Problem based learning into curriculum. It may be because they experienced the newer approach very useful and effective in learning when compared to conventional lectures. In a study by Wolfram and Stefan also, students had favoured PBL over lecture format. ${ }^{10}$

The reason for their likingness to PBL approach may be due to the numerous advantages of PBL which as they mentioned includes more interactive, enhances better memory, enhances better problem solving skills, self-directed learning, less boring and miscellaneous or others. Some researchers have even stated that PBL helps students acquire better critical thinking skills and creates a sense of responsibility towards self study. ${ }^{9}$

Never to forget, the PBL approach requires more man power and time for teaching. Also it needs additional time and effort spent on orienting the faculty and students to this new approach. Instead of 2 hours lectures, it takes nearly 4 to 5 hours spread across 2 weeks to teach a topic by PBL approach. The disadvantages of PBL as reported by many researchers includes its increased cost and faculty time, lower levels of content-specific knowledge and decreased learning efficiency. ${ }^{11}$ In our curriculum where time is an important factor, which should be kept in mind, teaching every topic of Physiology by PBL approach may not be feasible.
But for teaching some applied Physiology topics, it will be more effective than traditional lectures as our study has proven. In a study done by Neena Bhattacharya et al., in Physiology, majority of students also have favoured an integrated approach incorporating conventional teaching and PBL for a better learning outcome. ${ }^{12}$ The introduction of new PBL approach into medical curriculum may evoke interest and encouragement on the part of teachers to include this approach for teaching at least some applied Physiology topics.

\section{CONCLUSION:}

- $\quad$ PBL is a more effective method in teaching applied Physiology when compared to traditional lecture.

- Majority of students like to include it in the curriculum for teaching Physiology.

IMPLICATIONS: Our study has proven that Problem based learning approach is even more effective than traditional lectures for teaching applied Physiology topics. Students developed better problem solving skills with this newer approach, and so they are better equipped to apply their knowledge in real life situations. Due to the disadvantage of extra faculty and time requirements, this newer method can never replace our lectures.

But if judiciously combined with our conventional teaching, it can be very effective and useful for teaching Physiology. I think more studies should be taken up in other medical subjects also to know the effectiveness of this Problem based learning approach. I hope, inspired from our study many teachers may apply this Problem based learning approach for relevant topics during their teaching schedule.

\section{REFERENCES:}

1. Shalini Gupta, Ashwani K Gupta, Minni Verma, Harpreet Kaur, Amandeep Kaur, Kamaljit Singh. The attitudes and perceptions of medical students towards basic science subjects during their clinical years: A cross-sectional survey. International Journal of Applied and Basic Medical Research, Jan- Jun 2014, Vol 4, Issue 1.

2. Rita Sood, B V Adkoli. Medical Education in IndiaProblems and Prospects. Journal, Indian Academy of Clinical Medicine, Oct-Dec 2000, Vol 1,No3,210-212.

3. Woei Hung, David H Jonassen, Rude Liu. Problem Based Learning. Handbook on research on educational communications and technology. $3^{\text {rd }}$ edition, 01/2008: chapter 38: pages 485-506.

4. R .R. Abraham, P Vinod, M G Kamath, K Asha, K Ramnarayan. Learning approaches of undergraduate medical students to Physiology in a non-PBL and partially PBL-oriented curriculum. Adv Physiol Educ 32: 35-37, 2008.

5. PL Nandi, JNF Chan, CPK Chan, P Chan, LPK Chan. Undergraduate medical education: comparison of problem-based learning and conventional teaching. HKMJ 2000;6:301-6.

6. Bijli Nanda, Shankarappa Manjunatha. Indian medical students' perspectives on problem-based learning experiences in the undergraduate curriculum: One size does not fit all. J Educ Eval Health Prof 2013, 10:11. 
7. Redhwan Ahmed Al-Naggar and Yuri V Bobryshev. Acceptance of Problem Based Learning among Medical Students.

J Community Med Health Educ 2012, vol 2: issue 5.

8. Himanshu Pandya, Sarmishtha Ghosh. Sensitizing faculty to the problem-oriented approach as an instructional method: Experience of a brief faculty development workshop. The National Medical Journal of India vol. 21, no. 5, 2008 243-245.

9. Bajaj Preeti, Ahuja Ashish, Gosavi Shriram. Problem Based Learning (PBL)-An Effective Approach to Improve Learning Outcomes in Medical Teaching. Journal of Clinical and Diagnostic Research.

2013 Dec, Vol-7(12): 2896-2897.
10. Wolfram Antepohl \& Stefan Herzig. Problem-based learning versus lecture-based learning in a course of basic pharmacology: a controlled, randomized study. Medical Education 1999, 33,106-113.

11. Sajita Setia. Case Based Learning versus Problem Based Learning: A Direct Comparison from First Year Medical Students Perspective. Webmed Central Medical Education 2011; 2 (6).

12. Neena Bhattacharya, Nilima Shankar, Farah Khaliq, C. S. Rajesh, O. P. Tandon. Introducing problem based learning in physiology in the conventional Indian medical curriculum. Natl Med J India 2005; 18:92-5. 